02

\title{
Избирательная сольватация красителя 4-DASPI в бинарном растворителе вода-этиленгликоль
}

\author{
() А.С. Степко ${ }^{1}$, А.А. Медведева ${ }^{1}$, А.В. Кошкин ${ }^{1}$, П.В. Лебедев-Степанов ${ }^{1,2}$ \\ ${ }^{1}$ ФНИЦ „Кристаллография и фотоника“ РАН, \\ 108840 Москва, Россия \\ ${ }^{2}$ Национальный исследовательский ядерный университет „МИФИ“, \\ 119333 Москва, Россия \\ e-mail: tousen@bk.ru
}

Поступила в редакцию 22.06.2021 г.

В окончательной редакции 23.07.2021 г.

Принята к публикации 11.08.2021 г.

Экспериментально исследованы сольватохромные сдвиги максимумов спектров поглощения красителя 4DASPI (4-[4-(диметиламино)стирил]-1-метилпиридиния йодид) в бинарном растворителе вода-этиленгликоль в диапазоне концентраций 0-100\%. Построена зависимость сольватохромного сдвига от макроскопической диэлектрической проницаемости раствора и концентрации этиленгликоля. Для теоретической интерпретации применена модель Онзагера-Липтея, позволяющая произвести оценку эффективной диэлектрической проницаемости в микроскопической области, непосредственно примыкающей к хромофору, на основе значений измеренных сольватохромных сдвигов. Обнаружено, что значение диэлектрической проницаемости в сольватной оболочке данного красителя существенно отличается от макроскопического значения этой величины, так что оболочка значительно обогащена этиленгликолем (избирательная сольватация) во всем диапазоне концентраций, причем обогащение достигает максимума приблизительно в середине указанного диапазона. Обсужден состав сольватной оболочки красителя при различных значениях концентрации.

Ключевые слова: сольватохромный сдвиг, диэлектрическая проницаемость, избирательная сольватация.

DOI: $10.21883 /$ OS.2021.12.51737.2467-21

\section{Введение}

Исследование свойств многокомпонентных растворителей - важное направление современной фундаментальной и прикладной науки. Большинство биохимических процессов протекает в сложных многокомпонентных средах. Такие среды часто являются объектом исследования в медицинской диагностике и сенсорике [1], причем свойства среды в микроскопической области удобно анализировать спектроскопическими методами, исследуя изменение оптического спектра молекулызонда (или рецепторного центра) за счет влияния среды на электронные состояния хромофора. Особый интерес представляет использование молекул сольватохромных красителей в качестве зондов для гетерогенных сред, например для анализа процессов, протекающих при образовании твердой фазы в ходе золь-гель-синтеза [2], поскольку в условиях протекания реакции другие методы оказываются малоэффективными.

Расположение электронно-колебательных уровней органических красителей чувствительно к диэлектрической проницаемости окружения. Поэтому исследование спектров поглощения красителя, растворенного в среде, дает информацию о диэлектрической проницаемости в его сольватной оболочке, что позволит судить о наличии или преобладании в ней тех или иных компонентов раствора.
Известно, что локальные концентрации компонентов сложного растворителя вблизи молекулы растворенного вещества, как правило, отличаются от средних по раствору, так что сольватная оболочка обогащена тем компонентом растворителя, к которому указанная молекула имеет большее сродство. Происходит конкуренция молекул растворителя за место в непосредственной близости от исследуемой молекулы, приводящая к возникновению молекулярных образований (сольватов), микроскопический состав которых по крайней мере в пределах первой координационной сферы существенно отличается от макроскопической относительной доли частиц в растворе [3].

Если речь идет о бинарном растворе, макроскопическая концентрация компонентов которого задана изначально, значение сольватохромного сдвига в сольватной оболочке может дать информацию об отклонении эффективной диэлектрической проницаемости внутри нее от макроскопического значения указанной величины. Такое отличие свидетельствует об избирательной (выборочной) сольватации данного хромофора, т.е. об измененной локальной концентрации компонентов бинарного растворителя в сольватной оболочке по сравнению с макроскопическим значением концентрации раствора.

Если обсуждается бинарный раствор, один компонент которого относится к неполярным растворителям (например, толуол), а другой - к полярным (например, диметилсульфоксид), то при изменении бинарной 
концентрации растворителя, как правило, существенно меняется характер сольватации растворенной молекулы хромофора, которая в типичных случаях, например для цианиновых красителей, представляет собой ион, образующий контактную ионную пару со своим противоионом в неполярном растворителе, но при этом диссоциирует в полярном растворителе [4].

С переходом системы „ион красителя-противоион“ от состояния ионной пары к диссоциированному состоянию при изменении концентрации бинарного растворителя, состоящего из полярного и неполярного компонентов, значительную роль в изменении спектральных свойств хромофора играет изменение зарядового состояния хромофора в растворе. Данный эффект может доминировать, если дипольный момент красителя при переходе в возбужденное состояние меняется незначительно, так что универсальное диполь-дипольное взаимодействие растворенной молекулы с растворителем, а значит, и реакционное поле Онзагера [3] в такой системе невелико. Напротив, если оба компонента бинарного растворителя являются полярными, то можно полагать, что в первом приближении зарядовое состояние красителя не меняется, так что смещение спектра при изменении концентрации бинарного растворителя можно в значительной степени связать с диполь-дипольным взаимодействием.

В литературе, как правило, исследуется бинарная система, состоящая из полярного и неполярного растворителей. Так, в работе [5] исследована селективная неспецифическая сольватация 4диметиламинохалкона, служащего одним из эффективных спектрально-люминесцентных зондов, применяемых в медико-биологических исследованиях, в смеси гексана с ацетоном при малых концентрациях полярного компонента. Аналогично в работе [6] исследована сольватация того же красителя в смеси этилбензола с диметилформамидом. Как указывают авторы, особый интерес представляет получение экспериментальных данных о спектрах поглощения комплекса состава $1: 1$ при появлении в ближайшем окружении полярной молекулы красителя первой молекулы активного (полярного) растворителя (первичный сольватный комплекс). При этом, как показывает практика, спектр такого комплекса испытывает значительное красное смещение на величину $1000-2000 \mathrm{~cm}^{-1}$ [7].

Показано [5,6], что появление в ближайшем окружении молекулы красителя первой молекулы полярного растворителя (ацетона, диметилформамида) оказывает на спектр поглощения более сильное влияние, чем сольватная оболочка, целиком построенная из полярного компонента, так что парное взаимодействие полярных молекул носит преимущественно нелинейный характер (речь идет о комплексообразовании в окружении нейтрального компонента растворителя).

В работе [8] экспериментально исследовалось влияние мольной концентрации ОН-групп на полярность растворителя, а также избирательная сольватация красителя

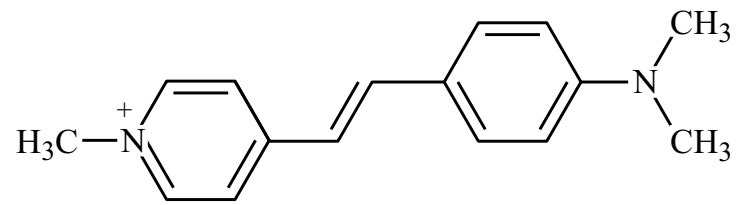

Pис. 1. Структурная формула красителя 4-DASPI.

пиридиний-N-феноксид бетаина в бинарном растворителе вода-спирт. На основе полученных данных сделан вывод, что в бинарной смеси не наблюдается линейной зависимости изменения диэлектрической проницаемости от мольной концентрации ОН-групп. Это вызвано наличием специфических взаимодействий в бинарной смеси вода-спирт. Наблюдалась избирательная сольватация красителя молекулами спирта.

В работе [9] исследовалась зависимость сольватохромного эффекта, наблюдаемого у пиридиниевых, бетаиновых и стириловых красителей, от полярности растворителя с точки зрения их использования как индикаторов полярности. На основе полученных данных был сделан вывод, что подбирать краситель в качестве зонда нужно с учетом наличия специфических взаимодействий красителя с различными типами растворителей.

Как выше указывалось, если компонентами бинарного растворителя ион красителя-противоион являются полярные жидкости, например вода и этиленгликоль, то можно полагать, что во всем диапазоне концентраций краситель существует в диссоциированном виде, не меняя зарядового состояния. Интерес к данной паре растворителей имеет как фундаментальный (исследование эффектов кластерообразования в растворе ассоциированных жидкостей), так и прикладной (использование в качестве фармацевтических наполнителей, косметических препаратов, промышленных и биологических растворителей, пищевых добавок и т. д.) аспекты [10-14].

В работе [13] экспериментально исследована избирательная сольватация стирилпиридиниевых красителей, таких как 4-DASPI (4-[4-(диметиламино)стирил]1-метилпиридиния бромид, рис. 1) и его разновидностей, отличающихся длиной алкильной цепи. Красители использовались в качестве зондов в бинарных смесях спиртов с гексаном, диоксаном и дихлорметаном. Предполагается, что в хромофоре, представленном на рис. 1, стириловая группа действует как донор, а пиридиниевый фрагмент, содержащий азот, - как акцептор. В работе показано, что данный тип красителя удобно использовать в качестве зонда, обладающего высокой чувствительностью к полярности растворителя. В чистых растворителях наблюдалось изменение сольватохромного сдвига в зависимости от диэлектрической проницаемости, позволяющее определить шкалу полярности растворителя. Варьирование полярности молекулы изменением алкильной цепи в зонде не могло повлиять на шкалу, поскольку сольватохромизм в чистом растворе обусловлен только хромофорной группой, одинаковой 
для рассматриваемых красителей. В бинарных смесях, когда один растворитель рассматривается как исходный (гексан, дихлорметан и диоксан), а другой - как сорастворитель (10 различных спиртов), были установлены эффекты избирательной сольватации, которые качественно интерпретируются рассмотрением взаимодействия растворителей с гидрофильными и гидрофобными группами зондов: полярный хромофор сосредоточивает около себя или ориентирует по направлению к себе в основном полярные группы молекул растворителя.

В настоящей работе экспериментально исследованы сольватохромные сдвиги максимумов спектров поглощения красителя 4-DASPI (рис. 1) в бинарном растворителе вода-этиленгликоль в диапазоне концентраций 0$100 \%$.

Этиленгликоль и его олигомеры имеют широкий спектр применения, включая использование в качестве фармацевтических наполнителей, косметических препаратов, промышленных и биологических растворителей, пищевых добавок и т.д. Взаимодействие этиленгликоля с водой является важным аспектом его применений. Данный тип бинарного растворителя (этиленгликольвода) ранее изучался как теоретически $[14,15]$, так и экспериментально [16].

В работах $[14,15]$ изучалось взаимодействие в комплексе этиленгликоль-вода с помощью многочастичного анализа методом функционала плотности и ab initio. Показано, что наиболее стабильными конформерами являются циклические структуры, в которых молекулы воды образуют мостик между двумя гидроксильными группами этиленгликоля.

В работе [16] экспериментально исследовалась диэлектрическая проницаемость раствора водаэтиленгликоль в диапазоне концентраций 0-100\% при комнатной температуре. Эти данные используются для интерпретации измерений зависимости сольватохромного сдвига красителя 4-DASPI от концентрации бинарного растворителя. Построена зависимость сольватохромного сдвига от макроскопической диэлектрической проницаемости раствора и концентрации этиленгликоля. Для теоретической интерпретации сдвигов применена модель Онзагера-Липтея, позволяющая произвести оценку эффективной диэлектрической проницаемости в микроскопической области, непосредственно примыкающей к хромофору, на основе значений измеренных сольватохромных сдвигов, что было ранее продемонстрировано в работе [17] для интерпретации сольватохромного сдвига 1-(3-аммонийпропил)-4-[(Е)-2-(3,4-диметоксифенил)-этенил-]-пиридиния в комплексе включения с кукурбитурилом, а в работе [18] при интерпретации сольватохромного сдвига 4-(2,4,6-трифенилпиридиний1-ил)-2,6-дифенил фенолят бетаина в бинарных растворителях вода-бутанол и вода-бутиламин. Сопоставление рассчитанной таким образом величины с табличным макроскопическим значением проницаемости позволяет судить об эффекте избирательной сольватации красителя и о составе его сольватной оболочки в зависимости от концентрации компонентов бинарного растворителя.

\section{Экспериментальная часть}

Базовый раствор 4-DASPI (Sigma-Aldrich) в дистиллированной воде с концентрацией $1.4 \cdot 10^{-5} \mathrm{~mol} / \mathrm{L}$ был приготовлен методом последовательного разбавления, после чего в стандартных кварцевых фотометрических кюветах на его основе готовились рабочие растворы красителя в смесях этиленгликоль (Sigma-Aldrich)-вода. Концентрация красителя во всех полученных растворах составляла $1 \cdot 10^{-5} \mathrm{~mol} / \mathrm{L}$, соотношение этиленгликольвода варьировало от 0 до 100\% этиленгликоля по объему с шагом 10\%. Спектры поглощения растворов красителя регистрировались на двухлучевом спектрофотометре UV-3101PC, в качестве образцов сравнения использовались аналогичные кюветы с дистиллированной водой.

Спектры поглощения 4-DASPI в растворах этиленгликоль-вода представляли собой широкие неструктурированные полосы. По мере роста концентрации этиленгликоля наблюдался батохромный сдвиг максимума поглощения красителя с уменьшением ширины полосы поглощения (рис. 2). Оба этих эффекта являются следствием изменения состава сольватной оболочки красителя. Батохромный сдвиг при уменьшении полярности растворителя является характерной особенностью 4-DASPI, обладающего обратным сольватохромизмом [12], в то время как рост вязкости среды приводит к уменьшению амплитуды колебательных и вращательных движений в молекуле, что приводит к уменьшению ширины электронноколебательного (вибронного) спектра [18].

Результаты измерений положений максимумов спектров поглощения в зависимости от объемной концентрации компонентов бинарного растворителя показаны на рис. 2.

Кроме того, было отмечено нелинейное изменение оптической плотности красителя (рис. 3). Уменьшение полярности раствора (диэлектрической постоянной) приводит к увеличению дипольного момента 4-DASPI за счет уменьшения валентных колебаний [13]. Это оказывает влияние на коэффициент экстинкции, который в свою очередь связан с оптической плотностью.

\section{Теоретическая часть}

Как правило, при достижении равновесия в смеси растворителей максимум спектра поглощения сольватированного в этой смеси красителя находится между положениями максимумов поглощения красителя в чистых компонентах этого растворителя. Однако наблюдаются случаи, когда максимум поглощения, получаемый в смеси, выходит за пределы указанного интервала. 

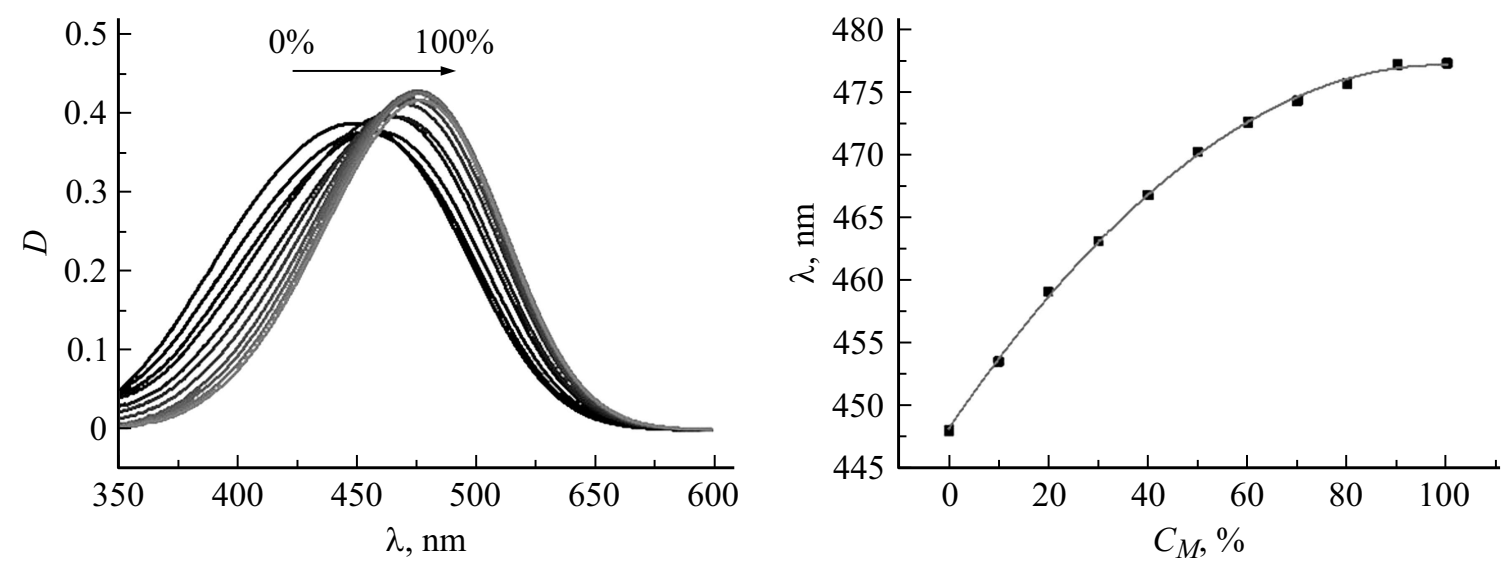

Рис. 2. Изменение спектра поглощения 4-DASPI в зависимости от содержания этиленгликоля (от 0 до $100 \%$ по объему) в бинарной смеси вода-этиленгликоль (слева). Изменение положения максимумов спектров поглощения (справа).

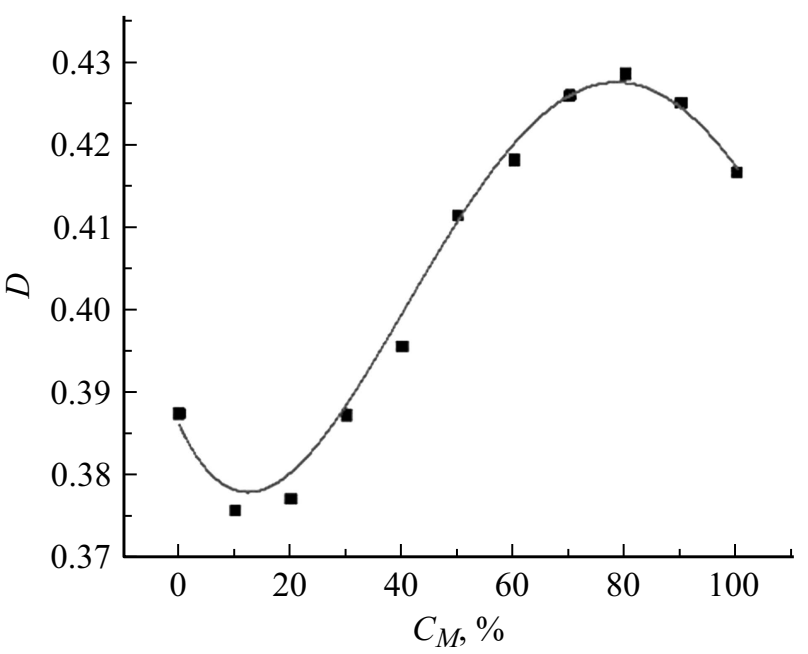

Рис. 3. Изменение оптической плотности растворов 4-DASPI с концентрацией $10^{-5} \mathrm{~mol} / \mathrm{L}$ в зависимости от состава растворителя.

Согласно [12], такой особенностью обладают некоторые бинарные растворы красителя 4-DASPI, а именно метанол-диоксан и диоксан-гексан. Авторы [13] в предположении конформационной жесткости красителя в этих растворителях в рассматриваемых пределах изменения концентрации связывают эти аномалии со специфическим взаимодействием компонентов бинарного растворителя в сольватной оболочке красителя, приводящим к существенной нелинейности поведения сольватохромного сдвига в зависимости от концентрации бинарного растворителя.

Изменение максимума спектра полярного хромофора 4-DASPI в полярных растворителях, рассматриваемых здесь, может быть объяснено с использованием представлений о неспецифическом диполь-дипольном взаимодействии, которое главным образом ответственно за сольватохромный эффект в таких системах. При этом сольватохромные эффекты объясняются отклонением эффективного локального значения показателя преломления растворителя в сольватной оболочке от среднего значения этого показателя в том же растворе вдали от сольватной оболочки. По этому отклонению можно судить о величине эффекта избирательной сольватации и предлагать модели структуры сольватной оболочки, которые отвечают локально измененному показателю преломления.

Изменения в спектрах 4-DASPI в различных условиях могут быть приближенно интерпретированы на основе теории Онзагера за счет диполь-дипольного взаимодействия красителя с молекулами растворителя.

В общем случае величина смещения частоты поглощения молекулы в растворе относительно молекулы в вакууме представляется в виде суммы вкладов дисперсионных, динамически поляризационных и ориентационноиндукционных взаимодействий $[3,17,18,19]$. Характерное время релаксации растворителя $\left(10^{-12} \mathrm{~s}\right)$ много меньше, чем время жизни возбужденного состояния $\left(10^{-9} \mathrm{~s}\right)$, поэтому необходимо учитывать не только индукционную, но и ориентационную поляризацию. Напротив, вклад дисперсионных и динамических поляризационных взаимодействий предполагается пренебрежимо малым, так как поляризуемость молекулы в основном и возбужденном состояниях мало различается и может быть принята приблизительно постоянной в расчетах. Данное приближение подтверждается большим количеством экспериментальных данных [19].

Согласно теории, молекула хромофора может быть представлена в виде сферы радиуса а, в центре которой расположен дипольный момент. В указанном приближении энергетический сдвиг электронных состояний, вызванный неспецифическими взаимодействиями, как следует из теории реакционного поля Онзагера, имеет вид $[17,19-21]$

$$
\begin{gathered}
\boldsymbol{\mu}=\boldsymbol{\mu}_{0}+\alpha \mathbf{E}_{R}, \\
\mathbf{E}_{R}=\left(f_{\text {ind }}+f_{\text {or }}\right) \boldsymbol{\mu},
\end{gathered}
$$




$$
\begin{gathered}
f_{\text {or }}=\frac{2}{\alpha^{3}}\left(\frac{\varepsilon-1}{2 \varepsilon+1}-\frac{n^{2}-1}{2 n^{2}+1}\right) \\
f_{\text {ind }}=\frac{2}{a^{3}}\left(\frac{n^{2}-1}{2 n^{2}+1}\right),
\end{gathered}
$$

где $\mathbf{E}_{R}$ - реакционное поле Онзагера; $\boldsymbol{\mu}$ - дипольный момент растворенной молекулы; $f_{\text {ind }}, f_{\text {or }}$ - индукционная и ориентационная функции отклика; $\boldsymbol{\mu}_{0}$ и $\boldsymbol{\alpha}-$ вектор дипольного момента и матрица поляризуемости молекулы в вакууме соответственно, $a$ - радиус полости растворителя; $\varepsilon$ и $n-$ диэлектрическая проницаемость и показатель преломления растворителя. При этом изменение волнового числа $\Delta v$ определяется по формуле

$h c \Delta v=$

$-\frac{1}{2}\left[\frac{2}{a^{3}}\left(\frac{n^{2}-1}{2 n^{2}+1}\right)\right]\left(\boldsymbol{\alpha}_{e}-\boldsymbol{\alpha}_{g}\right)\left[1-\frac{2}{a^{3}}\left(\frac{n^{2}-1}{2 n^{2}+1}\right) \boldsymbol{\alpha}\right]^{-}$

$\times\left(\boldsymbol{\mu}_{e}-\boldsymbol{\mu}_{g}\right)-\frac{2\left(\boldsymbol{\mu}_{e}-\boldsymbol{\alpha}_{g}\right)}{a^{3}}\left(\frac{\varepsilon-1}{2 \varepsilon+1}\right)\left[1-\frac{2}{a^{3}}\left(\frac{\varepsilon-1}{2 \varepsilon+1}\right) \alpha\right]^{-1} \boldsymbol{\mu}_{g}$,

где $\boldsymbol{\mu}_{e}, \boldsymbol{\mu}_{g}$ - векторы дипольных моментов возбужденного и основного состояний соответственно.

Для квантово-химических вычислений основного (равновесного) и франк-кондоновского возбужденного состояний использовался квантово-химический метод на основе теории зависящего от времени функционала электронной плотности или TDDFT (timedependent density-functional theory) c функционалом CAM-B3LYP в базисе 6-311G (d,p) в рамках программы Gamess (US). Ориентационно-индукционные части дипольных моментов (в дебаях) были вычислены для основного $\boldsymbol{\mu}_{g}=(7.98,-5.48,0.38)$ и возбужденного $\boldsymbol{\mu}_{e}=2.63,-1.77,0.54$ состояний 4-DASPI. Рассчитанная таким образом матрица поляризуемости (в атомных единицах, а. u.) имеет вид

$$
\alpha=\left(\begin{array}{ccc}
385.6 & -164.3 & -14.01 \\
-164.3 & 294.0 & -2.26 \\
-24.01 & -2.26 & 94.04
\end{array}\right)
$$

Для определения радиуса Онзагера были использованы литературные данные по сдвигам пиков спектров поглощения красителя 4-DASPI в ряде растворителей c различными диэлектрическими свойствами. Сдвиги спектров в разных растворителях относительно воды, определенные по формуле (1) с учетом известных (справочник [22]) значений $\varepsilon$ и $n$, помещены в табл. 1 вместе с экспериментально измеренными сдвигами, указанными в литературе [23]. Радиус Онзагера молекулы a при этом выступает подгоночным параметром. Наилучшее согласование с экспериментальными данными $(\Delta v, \varepsilon$ и $n)$ достигается при выборе размера молекулы $a=4.6 \AA$. На основе уравнения (1) проведено исследование зависимости сольватохромного сдвига красителя 4-DASPI в

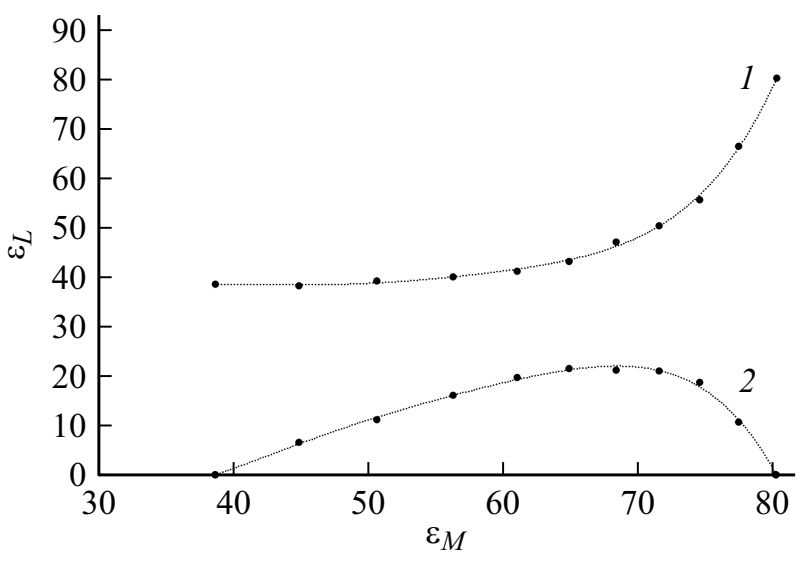

Рис. 4. Кривая 1 - локальное эффективное значение диэлектрической проницаемости бинарного растворителя $\varepsilon_{L}$ в малой области, непосредственно контактирующей с хромофором красителя 4-DASPI, как функция макроскопической диэлектрической проницаемости данного раствора $\varepsilon_{M}$. Кривая $2-$ разность макроскопической и локальной диэлектрических проницаемостей $\left(\varepsilon_{M}-\varepsilon_{L}\right)$.

смеси этиленгликоль-вода. Массовая доля этиленгликоля изменялась от 0 до $100 \%$.

С учетом полученного из калибровочного фитинга эффективного онзагеровского радиуса красителя проведен расчет зависимости сольватохромных сдвигов максимумов спектров поглощения 4-DASPI в бинарной смеси этиленгликоль-вода от величины диэлектрической проницаемости в локальной области раствора, в которую помещен хромофор красителя. В результате расчета для каждого экспериментально полученного спектрального сдвига было найдено то значение диэлектрической проницаемости, которое ему соответствует согласно формуле (1).

В табл. 2 помещены экспериментально полученные [12] и рассчитанные нами значения диэлектрической проницаемости, отвечающие заданным в эксперименте объемным долям бинарного растворителя (столбец $C_{M}$ ) при экспериментально измеренных нами сольватохромных сдвигах. При этом экспериментальное значение диэлектрической проницаемости $C_{M}$ является макроскопическим, т. е. усредненным по большому объему раствора, a расчетное значение $\varepsilon_{L}$, очевидно, соответствует локальной эффективной диэлектрической проницаемости в непосредственной близости к хромофору. Отличие двух этих величин для каждого значения $C_{M}$ (рис. 4) свидетельствует о наличии эффекта избирательной сольватации хромофора.

\section{Обсуждение}

Кривые, изображенные на рис. 4, свидетельствуют о существенном понижении эффективной диэлектрической проницаемости раствора вблизи хромофора красителя, что свидетельствует об обогащении этой 
Таблица 1. Расчетные и экспериментальные значения сдвигов спектров поглощения 4-DASPI в различных растворителях относительно $\mathrm{H}_{2} \mathrm{O}$

\begin{tabular}{|c|c|c|c|c|}
\hline Растворитель & $n$ & $\varepsilon$ & $\begin{array}{c}\text { Экспериментальные } \\
\text { сдвиги спектра } \\
\text { относительно } \mathrm{H}_{2} \mathrm{O}, \\
\mathrm{cm}^{-1}\end{array}$ & $\begin{array}{c}\text { Расчетные сдвиги } \\
\text { спектра } \\
\text { относительно } \\
\mathrm{H}_{2} \mathrm{O}, \mathrm{cm}^{-1}\end{array}$ \\
\hline ДХМ & 1.42 & 8.93 & -2929.36 & -2879 \\
\hline Октанол & 1.43 & 10.34 & -1524.83 & -2558 \\
\hline 2-Метил-2-пропанол & 1.40 & 12.47 & -1567.78 & -2136 \\
\hline Гексанол & 1.41 & 13.3 & -1779.91 & -2007 \\
\hline Пентанол & 1.40 & 13.9 & -1737.83 & -1921 \\
\hline Циклогексанол & 1.46 & 15 & -1905.12 & -1777 \\
\hline 2-бутанол & 1.39 & 16.56 & -1821.82 & -1600 \\
\hline 1-бутанол & 1.39 & 17.51 & -1653.16 & -1505 \\
\hline 2-пропанол & 1.37 & 19.92 & -1524.83 & -1298 \\
\hline 1-пропанол & 1.38 & 20.45 & -1610.56 & -1259 \\
\hline Ацетон & 1.36 & 20.56 & -1307.35 & -1250 \\
\hline Этанол & 1.36 & 24.55 & -1438.38 & -1000 \\
\hline Метанол & 1.33 & 32.66 & -1219.08 & -660 \\
\hline Ацетонитрил & 1.34 & 35.94 & -1040.29 & -562 \\
\hline ДМФА & 1.30 & 36.71 & -995.119 & -541 \\
\hline Этиленгликоль & 1.35 & 37.3 & -1394.89 & -526 \\
\hline ДМАА & 1.55 & 37.78 & -1040.29 & -513 \\
\hline ДМСО & 1.48 & 46.45 & -995.119 & -334 \\
\hline Вода & 1.33 & 78.36 & 0 & 0 \\
\hline
\end{tabular}

Таблица 2. Средние и локальные характеристики бинарного раствора 4-DASPI

\begin{tabular}{|c|c|c|c|c|c|c|c|}
\hline$C_{M}, \%$ & $\lambda, \mathrm{cm}^{-1}$ & $\begin{array}{c}\Delta \lambda \\
\text { относительно } \\
\mathrm{H}_{2} \mathrm{O}, \mathrm{cm}^{-1}\end{array}$ & $\varepsilon_{M}$ & $\chi_{M}$ & $\varepsilon_{L}$ & $C_{L}, \%$ & $X_{L}$ \\
\hline 0 & 22271.71 & 0 & 79.88 & 0.00 & 80.37 & 0 & 0.00 \\
\hline 10 & 22002.20 & -269.51 & 77.34 & 0.03 & 66.67 & 41.73 & 0.19 \\
\hline 20 & 21691.97 & -579.74 & 74.44 & 0.07 & 55.71 & 68.78 & 0.42 \\
\hline 30 & 21505.38 & -766.34 & 71.19 & 0.12 & 50.5 & 79.56 & 0.56 \\
\hline 40 & 21367.52 & -904.19 & 67.57 & 0.18 & 47.18 & 85.73 & 0.66 \\
\hline 50 & 21186.44 & -1085.27 & 63.59 & 0.24 & 43.36 & 92.16 & 0.79 \\
\hline 60 & 21074.82 & -1196.90 & 59.25 & 0.33 & 41.29 & 95.34 & 0.87 \\
\hline 70 & 21008.40 & -1263.31 & 54.55 & 0.43 & 45.10 & 97.07 & 0.91 \\
\hline 80 & 20964.36 & -1307.35 & 49.49 & 0.56 & 39.36 & 98.11 & 0.94 \\
\hline 90 & 20898.64 & -1373.07 & 44.08 & 0.74 & 38.29 & 99.57 & 0.99 \\
\hline 100 & 20920.50 & -1351.21 & 38.30 & 1.00 & 38.66 & 100 & 1.00 \\
\hline
\end{tabular}

Примечание. Обозначения: $C_{M}$ и $C_{L}-$ соответственно макроскопическая и локальная (в малой области около хромофора 4-DASPI) объемные доли этиленгликоля в бинарном растворителе; $X_{M}$ и $X_{L}-$ соответственно макроскопическая и локальная мольные доли этиленгликоля в растворе; $\lambda-$ экспериментальный максимум спектра поглощения 4-DASPI; $\Delta \lambda$ - экспериментальный сдвиг спектра поглощения относительно $100 \%$ раствора воды; $\varepsilon_{M}$ и $\varepsilon_{L}-$ соответственно макроскопическое и локальное значения диэлектрической проницаемости.

локальной области этиленгликолем и соответственно об обеднении ее молекулами воды, имеющей большую диэлектрическую проницаемость, чем этиленгликоль.

Имея зависимость макроскопического значения диэлектрической проницаемости от концентрации раствора, можно в линейном приближении оценить локальное изменение концентрации бинарного растворителя около хромофора, предполагая, что и в наномасштабах зави- симость $\varepsilon$ от $C$, имеющая место для макроскопических объемов раствора, приблизительно сохраняется. Рассчитанные таким образом локальные значения объемной доли этиленгликоля $C_{L}$ помещены в табл. 2 вместе с соответствующей мольной долей этиленгликоля $X_{L}$. Рядом помещена макроскопическая мольная доля $X_{M}$, отвечающая макроскопической объемной доли этиленгликоля $C_{M}$. 


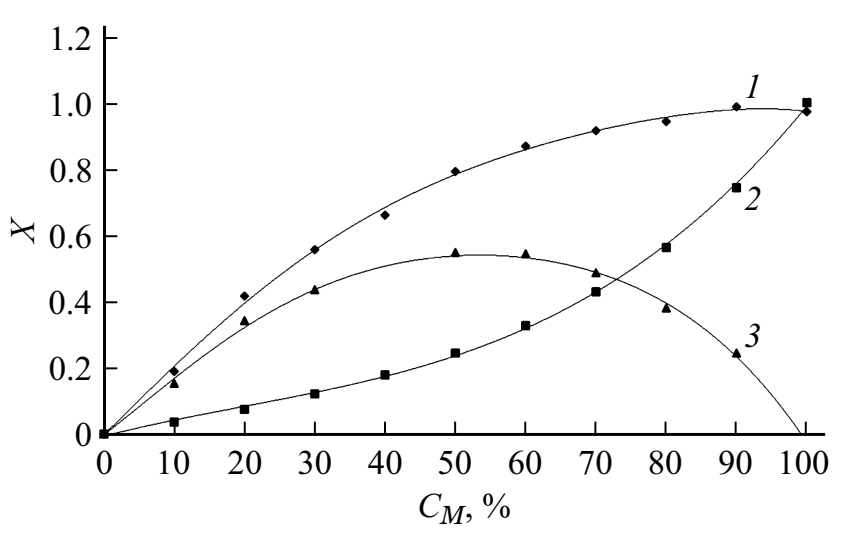

Рис. 5. Зависимости локальной мольной доли этиленгликоля $X_{L}$ (кривая 1$)$, макроскопической мольной доли его $X_{M}$ (кривая 2) и разности $X_{L}-X_{M}$ (кривая 3 ) от макроскопической объемной доли этиленгликоля $C_{M}$.

На рис. 5 показана зависимость оцененной таким образом локальной мольной доли этиленгликоля в бинарном растворителе от его макроскопической объемной доли, задаваемой в проведенном эксперименте.

Максимум разности $X_{L}-X_{M}$ отвечает примерно 50\% макроскопической объемной концентрации. При этом $X_{L}$ достигает приблизительно 0.8 , что означает, что на одну молекулу воды приходится примерно 4 молекулы этиленгликоля, тогда как макроскопическая мольная доля этиленгликоля при этом составляет 0.24, т.е. соотношение молекул воды и этиленгликоля в объеме раствора практически обратное - на три молекулы воды приходится одна молекула этиленгликоля. Фактически при средних макроскопических объемных долях этиленгликоля свыше 50\% можно полагать, что сольватная оболочка хромофора 4-DASPI практически полностью состоит из этиленгликоля.

Заметим, что макроскопической объемной доле этиленгликоля около $50 \%$ приблизительно отвечает точка перегиба на графике оптической плотности, представленном на рис. 3. Это может быть связано с уплотнением или расширением сольватной оболочки, с существенным преобладанием этиленгликоля в окружении толщи бинарного раствора с преобладанием воды, что способствует увеличению потерь энергии падающего света. Минимум на кривой, представленной на рис. 3 $\left(C_{M}\right.$ около $\left.10 \%\right)$ отвечает локальному соотношению 4 молекулы воды на одну молекулу этиленгликоля (при макроскопической мольной доле 9 молекул воды на одну молекулу этиленгликоля), что может указывать на состав сольватного комплекса 4-DASPI в данном бинарном растворителе с наименьшим поглощением, важную роль в формировании которого играет специфическое взаимодействие двух растворителей в окрестностях хромофора.

\section{Заключение}

В работе впервые представлены результаты эксперимента по исследованию спектра поглощения красителя 4-DASPI в бинарном растворителе этиленгликоль-вода при изменении доли этиленгликоля от 0 до 100\%. Из эксперимента получены зависимости положения максимума спектра поглощения и оптической плотности от концентрации бинарного растворителя.

Опираясь на экспериментальные данные по положениям максимумов спектра поглощения, на основе модели Онзагера-Липтея были найдены соответствующие этим положениям эффективные диэлектрические проницаемости растворов. Значения диэлектрической проницаемости, полученные из расчета, очевидно, соответствующие сольватной оболочке красителя, существенно отличаются от известных табличных значений макроскопической диэлектрической проницаемости для тех концентраций бинарного растворителя, которые были взяты в эксперименте, что указывает на эффект избирательной сольватации. При этом характер отклонения локальной диэлектрической проницаемости в сольватной оболочке от табличных значений свидетельствует о существенном обогащении сольватной оболочки этиленгликолем.

Произведена оценка локального изменения мольной доли этиленгликоля в сольватной оболочке хромофора 4-DASPI. Показано, что приблизительно в середине диапазона изменения макроскопической объемной доли имеет место абсолютный максимум отличия локальной и макроскопической концентраций. В этой точке происходит перестройка сольватной оболочки, характеризующаяся практически полным доминированием этиленгликоля над водой, что соответствует точке перегиба на графике изменения оптической плотности с концентрацией.

Молекулярно-динамические и квантово-химические расчеты с явным рассмотрением молекул растворителя чрезвычайно сложны, ресурсоемки и малонадежны в связи с практическими ограничениями на размеры системы. В этой связи предлагаемый метод расчета относительно прост и позволяет выявить, по крайней мере в полуколичественном приближении, наличие и основные особенности избирательной сольватации в полярных растворителях, состав сольватной оболочки, а также построить шкалу полярности на основе бинарного раствора с учетом избирательной сольватации хромофоpa.

\section{Финансирование работы}

Работа выполнена при поддержке Министерства науки и высшего образования в рамках выполнения работ по Государственному заданию ФНИЦ „Кристаллография и фотоника" РАН.

\section{Конфликт интересов}

Авторы заявляют, что у них нет конфликта интересов. 


\section{Список литературы}

[1] Valeur B. Molecular Fluorescence: Principles and Applications. Wiley-VCH Verlag $\mathrm{GmbH}, 2001.381 \mathrm{p}$.

[2] Кошкин А.В., Медведева А.А., Лобова Н.А. // Химия высоких энергий. 2019. Т. 53. № 6. С. 448.

[3] Бахшиев Н.Г. Спектроскопия межмолекулярных взаимодействий. Л.: Наука, 1972. 264 с.

[4] Одиноков А.В., Базилевский М.В., Петров Н.Х., Чибисов А.К., Алфимов М.В. // Химия высоких энергий. 2010. T. 44. № 5. C. 408.

[5] Кириллова А.Ю., Свердлова О.В., Бахшиев Н.Г. // Опт. и спектр. 2007. Т. 102. № 4. С. 599.

[6] Бахшиев Н.Г., Гуларян С.К., Добрецов Г.Е., Кириллова А.Ю., Светличный В.Ю. // Опт. и спектр. 2008. Т. 104. № 5. C. 809.

[7] Бахшиев Н.Г. Фотофизика диполь-дипольных взаимодействий: Процессы сольватации и комплексообразования. Изд-во Санкт-Петербургского государственного университета, 2006. $500 \mathrm{c}$.

[8] Bentley T.W., In S.K. // Org. Biomol. Chem. 2004. V. 2. P. 2376.

[9] Reichardt C. // Chem. Rev. 1994. V. 94. P. 2319.

[10] Shinyashiki N., Ashaka N., Mashimo S., Yagihara S. // J. Chem. Phys. 1990. V. 93. P. 760.

[11] Saha U., Ghosh R. // J. Phys. D. 1999. V. 32. P. 820.

[12] Zahn M., Ohki Y., Fenneman D.B., Gripshover R.J., Gehman V.H. // Proc. IEEE. 1986. V. 74. N 9. P. 1182.

[13] Panigrahi M., Dash S., Patel S., Mishra B.K. // J. Phys. Chem. B. 2011. V. 115. P. 99.

[14] Chaudhari A., Lee S.-L. // J. Chem. Phys. 2004. V. 120. N 16. P. 7464.

[15] Mahesh Kumar R., Baskar P., Balamurugan K., Das S., Subramanian V. // J. Phys. Chem. A. 2012. V. 116. P. 4239.

[16] Douheret G., Morena M. Can. // J. Chem. 1979. V. 57. P. 608.

[17] Степко А.С., Лобова Н.А., Лебедев-Степанов П.В. // Опт. и спектр. 2019. Т. 126. № 4. С. 391.

[18] Stepko A.S., Savenko O.A., Lebedev-Stepanov P.V. // J. Phys.: Conf. Ser. 2021. V. 1919. P. 012008.

[19] Komarov P.V., Plotnikov V.G. // Intern. J. Quant. Chem. 2012. V. 112. P. 3039

[20] Lebedev-Stepanov P.V. // AIP Advances. 2021. V. 11. P. 035115.

[21] Modern Quantum Chemistry. Part II: Interactions. / Ed. by Liptay W., Sinanoglu O. NY.: Academic Press, 1965. P. 282 (Chapter 5).

[22] CRC Handbook of Chemistry and Physics. 98th Edition. CRC Press, 2017. P. 2616.

[23] Panigrah M., Dash S., Patel S., Mishra B.K. // J. Phys. Chem. B. 2011. V. 115. P. 99. 